\title{
ANÁLISE CRÍTICA DO ENTENDIMENTO DO SUPREMO TRIBUNAL FEDERAL NO JULGAMENTO DA ADI 5881
}

Resumo: O presente artigo tem como objetivo analisar o julgamento da ADI 5881 pelo Supremo Tribunal Federal e a elaboração de argumentos críticos a respeito. Assim, o tema problema reside na averiguação de (des)acerto dos fundamentos utilizados no julgado. Utilizar-se-á da pesquisa bibliográfica por meio do método dedutivo e comparativo, além de pesquisa de dados para, em conclusão, asseverar que os fundamentos sedimentados pelo STF não se sustentam, sendo passíveis de superação e alteração do resultado alcançado.

Palavras-chave: Ação de Execução Fiscal, Ineficiência, Argumentos, Supremo Tribunal Federal, ADI 5881.

\section{CRITICAL ANALYSIS OF THE BRAZILIAN SUPREME COURT UNDERSTANDING IN THE TRIAL OF ADI 5881}

Abstract: This article aims to analyze the trial of the ADI 5881 by the Brazilian Supreme Court and prepare critical arguments about. Thus, the question is inquirity of the correct arguments referred to in the trial. The bibliographic research will be used through the deductive and comparative method, as well as data research to, in conclusion, assert that the arguments are surpassable, what would lead the change of result.

Keywords: Tax enforcement, Inefficiency, Arguments, Brazilian Supreme Court, ADI 5881.

\section{INTRODUÇÃO}

Diante de um cenário de "inexecução fiscal" por meio do procedimento estabelecido pela Lei 6.830/80 (BRASIL, 1980), a Lei 10.522/02 (BRASIL, 2002) foi legislativamente oxigenada pela Lei 13.606/18 (BRASIL, 2018), para, entre outros assuntos, prescrever a possibilidade do instituto administrativo da averbação pré-executória, em sede de executivos fiscais federais.

No entanto, a alteração normativa levada a efeito gerou críticas e insurgências judiciais, a exemplo da ação direta de inconstitucionalidade (ADI) 5.881 (BRASIL, Supremo Tribunal Federal, 2020), em conjunto com as ADI’s 5.886, 5.890, 5.925, 5.931 e 5.932,

\footnotetext{
${ }^{1}$ Mestre em Direito pela Universidade Fumec. Especialista em Processo pela Puc-Minas. Procurador do Município de Contagem/MG. Membro do Conselho Tributário Administrativo do Município de Contagem. Vice-Presidente da Comissão de Advocacia Pública da OAB/Contagem. Fundador e ex Presidente da Associação dos Procuradores do Município de Contagem. Advogado. E-mail: leobrarocha@ gmail.com
} 
quanto ao art. 25 da Lei 13.606/18 (BRASIL, 2018), o qual propiciou, exatamente, o instituto sob apreço.

As ADI’s foram distribuídas sob a relatoria do ministro Marco Aurélio, que entendeu pela inconstitucionalidade do dispositivo impugnado.

Por maioria, o Supremo Tribunal Federal (STF), nos termos do voto médio do ministro Luis Roberto Barroso, julgou parcialmente procedentes os pedidos lançados nas já citadas ADI's, de modo a considerar inconstitucional a expressão “... tornando-os indisponíveis", descrita na parte final do inciso III do $\S 3^{\circ}$ do art. 20-B da Lei 10.522/02 (BRASIL, 2002), com a redação que lhe foi emprestada pela Lei 13.606/18 (BRASIL, 2018), com o que não se concorda, em absoluto.

Assim, o tema problema reside na verificação do (des)acerto do entendimento sedimentado pelo Supremo Tribunal Federal. Parte-se da hipótese de que o procedimento instituído pela Lei 10.522/02 não goza de inconstitucionalidade. Utilizar-se-á da pesquisa bibliográfica por meio dos métodos dedutivo e comparativo, além de pesquisa de dados para, em conclusão, asseverar que o julgamento sob análise pecou na conclusão jurídica de pretensa inconstitucionalidade do instituto da averbação pré-executória.

Pois bem, vencida a parte introdutória, deve-se mencionar que o presente artigo é dividido em quatro partes.

$\mathrm{Na}$ primeira, será abordada a ação de execução fiscal como instrumento arrecadatório.

Na segunda parte, analisar-se-á a alteração da Lei 10.522/02 (BRASIL, 2002), por meio da Lei 13.606/18 (BRASIL, 2018), notadamente quanto ao instituto da averbação préexecutória e sedimentação do julgado na ADI 5881 pelo Supremo Tribunal Federal.

A terceira parte é destinada à análise crítica do respectivo julgado.

$\mathrm{Na}$ parte final do artigo, já conclusiva, em adição ao lançamento de contrapontos relativamente ao entendimento do STF, aborda-se a imperiosa necessidade de remodelamento da cobrança tributária no Brasil.

\section{A EXECUÇÃO FISCAL COMO INSTRUMENTO² ARRECADATÓRIO}

\footnotetext{
${ }^{2}$ Neste trabalho, o termo instrumento é lançado sem correlação com a perspectiva da escola instrumentalista do processo, cunhada por Oskar Von Bulow.
} 
A tributação não se distancia da perspectiva política, gerando efeitos não somente no aspecto financeiro, pois que sem tributos a consecução de ações em prol da coletividade se torna impossível (FONSECA; FONSECA, 2017).

Os tributos, portanto, não devem ser apequenados meramente à faceta arrecadatória, mas devem ser enxergados, também, como meio de financiamento do Estado e, por conseguinte, dos direitos fundamentais.

Sob esta perspectiva, afasta-se da compulsória tributação a pecha de "... expropriação indevida ou instrumento de manipulação governamental." (RIBEIRO; NUNES; ALMEIDA, 2018). A tributação é indissociável do Estado.

A ação de execução fiscal é procedimento diferenciado, por vezes menos solene do que o prescrito no Código de Processo Civil (CPC) (BRASIL, 2015), e com prerrogativas à Fazenda Pública. Adverte-se que o tratamento à execução fiscal neste artigo se dará, exclusivamente, quanto à arrecadação de tributos, pelas pessoas jurídicas de direito público, a saber, União, Estados, Distrito Federal e Municípios, não se desconhecendo a legitimação ativa mais abrangente e a possibilidade de se executar créditos não tributários.

É inegável que a Lei 6.830/80 (BRASIL, 1980), denominada Lei de Execuções Fiscais (LEF) objetiva que a arrecadação tributária se dê rapidamente, para fins de aplicação do montante captado em prol da coletividade (CAIS, 2013).

Isto porque o débito tributário inadimplido gera duas importantes consequências: (i) ausência de implementação de políticas públicas universais e gratuitas; (ii) descrédito do procedimental legalmente apontado para fim arrecadatório (FONSECA; FONSECA, 2017).

A ação de execução fiscal, portanto, pode ser conceituada como “... uma espécie de processo de execução por quantia certa, fundado em título extrajudicial, através do qual se busca a prestação da tutela jurisdicional executiva." (MACHADO SEGUNDO, 2014, p. 225).

Desta feita, a ação em voga, sob o influxo do interesse público, e, exatamente em razão deste, prevê a mitigação de certas formalidades, relativamente à execução entre particulares, com o desiderato, além dos extrafiscais, de arrecadação tributária, inarredável à consecução das políticas públicas insertas na Constituição da República Federativa do Brasil de 1988 (CR/88) (BRASIL, 1988).

Foi a identificação do interesse público que gravita em torno da ação de execução fiscal, a qual propicia a cobrança de créditos tributários, que ensejou a publicação da Lei 
6.830/80 (BRASIL, 1980), aparelhando a Fazenda Pública de instrumento propício, fundado na perspectiva da eficiência, para fins de arrecadação tributária.

Ocorre que, ainda assim, a despeito do desapego extremamente formal do procedimento da ação de execução fiscal, em contraponto à execução entre particulares, aquela encontra óbices de toda sorte para a consecução dos seus objetivos.

Não é por outro motivo que o Conselho Nacional de Justiça $(\mathrm{CNJ})$ por meio do Relatório Justiça em números 2020, aponta, historicamente, a execução fiscal “... como o principal fator de morosidade do Poder Judiciário." (CONSELHO, 2020, p. 155).

De modo a comprovar a assertiva supra, o mesmo relatório indica que as execuções fiscais representam 39\% do total dos casos pendentes de julgamento e $70 \%$ das execuções em curso no Brasil. De igual forma, remonta taxa de congestionamento de $87 \%$, isto é, de cada 100 processos desta natureza que tramitaram no ano de $2019^{3}$, somente 13 foram baixados (CONSELHO, 2020).

Ainda, aponta o relatório que as execuções fiscais representam $48 \%$ do total do acervo processual da Justiça Federal, enquanto que na Justiça Estadual o percentual é pouco menor: 43\% (CONSELHO, 2020).

Lado outro, de forma inédita na série histórica do relatório, ainda que não substancial em relação ao todo, houve decréscimo de execuções fiscais, equivalente a $0,4 \%$ (CONSELHO, 2019), crescente a 3,3\% no último relatório (CONSELHO, 2020). Ainda assim, o tempo de giro do acervo específico, isto é, necessário ao julgamento de todas as ações de execução fiscal pendentes, sem a distribuição de qualquer outra, pressupõe o decurso de 08 anos na Justiça Estadual e de 10 anos na Federal (CONSELHO, 2020). Uma situação alarmante $!^{4}$

Ainda, o Relatório do CNJ indica a execução, como um todo, como problemática, notadamente a fiscal. Isto porque, no Judiciário ingressam quase duas vezes mais ações de conhecimento do que de execução. No entanto, o acervo apresenta ordem inversa, já que

\footnotetext{
${ }^{3}$ O Relatório CNJ em números 2020, publicado neste ano, faz referência a dados do ano antecedente, 2019 na hipótese.

${ }^{4}$ Soma-se ao descrito, o fato de que o Relatório do CNJ leva em consideração apenas a atividade tipicamente prestada pela função jurisdicional, não se incluindo nesta análise o elevado número de processos tributários administrativos (PTA'S) em curso perante a União, Estados, Distrito Federal e Municípios. Nesta perspectiva, não se pode desconsiderar que o processo administrativo fiscal dura, em média, 08 anos (QUEIROZ E SILVA, 2016), o qual, somado ao tempo de duração da ação de execução fiscal, dá margem ao esvaziamento patrimonial do devedor e, a reboque, a ineficiência arrecadatória.
} 
aproximadamente 54,5\% dos feitos pendentes de julgamento são de execução, e destes $70 \%$ são fiscais (CONSELHO, 2020).

Reflexo desses dados é a completa impossibilidade de gestão da Administração Pública, impedindo planejamento administrativo e orçamentário relativamente aos valores em execução, notadamente em razão da periodicidade das leis orçamentárias. Trabalha-se, portanto, com prognósticos, desequlibrando-se a salutar provisão exigida entre receitas e despesas públicas.

Nem mesmo a especialização é capaz de abrandar a conjuntura, uma vez que dos processos de execução fiscal, 93,5\% estão em varas exclusivas, de execução fiscal ou de Fazenda Pública (CONSELHO, 2020).

Outro aspecto que denota percalço na utilização da ação de execução fiscal está diretamente ligado à baixa taxa de recuperação do crédito inscrito em dívida ativa.

Do Relatório PFGN em números 2020, com dados relativos ao ano de 2019, infere-se que a dívida ativa da União remontou, neste exercício, $\mathrm{R} \$ 2.436$ trilhões, dos quais $\mathrm{R} \$$ 7.109.619.085,38 foram arrecadados por meio de execução forçada, leia-se, valendo-se de execução fiscal (PROCURADORIA, 2020). Percentualmente, equivale a 0,29\% do total da dívida ativa arrecadado em um ano. Inobstante nominalmente expressiva a quantia arrecadada, percentualmente não o é, nem de longe.

Em reportagem veiculada no site da Procuradoria Geral da Fazenda Nacional (PGFN), no ano de 2016, evidenciou-se que, no período de março de 2013 a outubro de 2015, o patamar de recuperação da ação de execução fiscal girou em torno de $1 \%$. Lado outro, no mesmo período, o percentual de recuperação do protesto foi de 19,2\% (PROCURADORIA, 2016).

Em 2007 foi publicado, pelo Ministério da Justiça, estudo sobre execuções fiscais no Brasil, que classifica os dados destas como aterradores, sugerindo-se a desjudicialização do procedimento, com dotação de definitividade na esfera administrativa (MINISTÉRIO, 2007). Trata-se, exatamente, do modelo adotado no Peru (GODOY, 2009).

Não à toa, o protesto de certidão de dívida ativa $(\mathrm{CDA})^{5}$ e outras formas de extrajudiciais de cobrança tributária são crescentes, não só numérica, mas em especial percentualmente em relação à ação executiva fiscal.

\footnotetext{
${ }^{5}$ A CDA pode ser conceituada como o título executivo extrajudicial que instrui a ação de execução fiscal.
} 


\section{ALTERAÇÃO DA LEI 10.522/02 PELA LEI 13.606/18 E JULGAMENTO DA ADI 5881 PELO SUPREMO TRIBUNAL FEDERAL}

O cenário de "inexecução fiscal” propiciou que a Lei 10.522/02 (BRASIL, 2002), a qual originariamente versa sobre o Cadastro Informativo de Créditos não Quitados de Órgãos e Entidades Federais (CADIN), tenha sido, ao longo do tempo, legislativamente retalhada, o que culminou na previsão de outros institutos diversos daquele.

Mais recentemente, sem dúvida, o de maior interesse e polêmica, e que poderia potencializar a recuperação de crédito via ação de execução fiscal, adveio da alteração perpetrada pela Lei 13.606/18 (BRASIL, 2018), notadamente quanto à averbação préexecutória, com o intuito de dotar o modelo de cobrança do crédito tributário federal de instrumento que propicie mais celeridade na consecução do objetivo traçado.

$\mathrm{O}$ instituto em voga, regulamentado pela Portaria PGFN 33/2018 (PROCURADORIA, 2018a), garantiu a inserção do art. 20-B, §3º, II e art. 20-E na Lei 10.522/02 (BRASIL, 2002), com a possibilidade de averbação da CDA em órgãos registrais de bens e direitos sujeitos a arresto e penhora, de forma a gravá-los com a indisponibilidade.

Perceba-se, de plano, que o lançamento de indisponibilidade não pode ser equiparado à expropriação de bens, pois que, por si só, não dá ensejo à alteração de propriedade.

Ainda, possibilitou à PGFN a edição de ato complementar ao cumprimento de tal faculdade procedimental, razão pela qual, conforme alhures já adiantado, foi publicada a Portaria PGFN 33/2018 (PROCURADORIA, 2018a).

Instaurou-se, na esfera federal, pois que o regramento normativo não foi destinado a pessoa jurídica diversa da União, um verdadeiro procedimento híbrido, com a consecução de atos de garantia na esfera administrativa, julgamento de impugnação de mesma natureza e posterior distribuição da ação de execução fiscal perante o Judiciário.

A oxigenação legislativa predispõe que, inobstante não obrigatória a distribuição da ação de execução fiscal, atentando-se aos mais expressivos, mas não necessariamente eficientes resultados alcançados por via de instrumentos extrajudiciais de arrecadação, o intento não é de abandono daquela, mas sim a utilização, na esfera federal, em consonância com os preceitos da lei, de modo a ostentar fase administrativa, sem prejuízo da judicial.

No entanto, logicamente, a alteração normativa levada a efeito gerou críticas e insurgências judiciais, a exemplo da ADI 5.881 (BRASIL, Supremo Tribunal Federal, 2020), 
em conjunto com as ADI's 5.886, 5.890, 5.925, 5.931 e 5.932, quanto ao art. 25 da Lei 13.606/18 (BRASIL, 2018), o qual propiciou, exatamente, o instituto sob apreço.

As ADI’s foram distribuídas sob a relatoria do ministro Marco Aurélio, que entendeu pela inconstitucionalidade do dispositivo impugnado.

Em fundamentação ao seu voto, o ministro relator asseverou que o art. 25 da Lei 13.606/18 (BRASIL, 2018) gozaria de inconstitucionalidade formal, pois que atuaria ao arrepio do disposto no art. 146, III, "b" da CR/88, uma vez que na locução "crédito tributário" estariam insertos os instrumentos legais para efetivação da cobrança pela Fazenda Pública. Na hipótese, exemplificou que o lançamento de indisponibilidade, prescrito no art. 185-A do Código Tributário Nacional, foi inserido em norma com status de lei complementar, diferentemente na natureza ordinária da lei sob enfoque (SUPREMO, 2020a). Seguiram o relator, os ministros Nunes Marques (SUPREMO, 2020b) e Luiz Edson Fachin (SUPREMO, 2020c).

Do mesmo entendimento, comungam Glauber Mesquita e Rafhael Frattari, ao argumento de sistematicidade da ordem tributária, gravando-a com racionalidade e uniformidade (MESQUITA; FRATTARI, 2018).

$\mathrm{Na}$ perspectiva material, o ministro relator entendeu haver inconstitucionalidade, ao designar que:

\footnotetext{
"Com a edição da norma impugnada, a instituir a denominada "averbação préexecutória", o legislador ordinário promoveu verdadeiro desvirtuamento do sistema de cobrança da dívida ativa da União, ante a previsão de espécie de execução administrativa dos débitos, em desarmonia com as balizas constitucionais no sentido de obstar ao máximo o exercício da autotutela pelo Estado. [...] Constitui passo demasiadamente largo, incompatível com os princípios constitucionais do contraditório e da ampla defesa - artigo $5^{\circ}$, inciso LV, da Constituição Federal -, franquear-se à Administração [...] o poder de bloquear unilateralmente os bens de contribuintes inscritos em dívida ativa, ausente intervenção do Estado Juiz, levandose em conta a necessidade de a Fazenda Pública buscar o Judiciário visando à cobrança, mediante o adequado processo executivo fiscal, do que devido.

Surge inviável, sob qualquer ângulo de análise, compatibilizar o previsto na norma questionada com o disposto no artigo $5^{\circ}$, inciso LIV, da Constituição Federal, segundo o qual "ninguém será privado da liberdade ou de seus bens sem o devido processo legal", diretriz ínsita ao regular funcionamento do Estado Democrático de Direito." (BRASIL, Supremo Tribunal Federal, 2020a).
}

Ainda, o ministro citou o art. 185-A do Código Tributário Nacional (CTN) (BRASIL, 1966), outrora já referido, o qual determina, mediante chancela judicial e após o esgotamento na localização de bens penhoráveis, o lançamento da indisponibilidade, com 
relevo à origem do dispositivo na Lei Complementar 118/05 (BRASIL, 2005) (BRASIL, Supremo Tribunal Federal, 2020a).

Por fim, o relator entendeu que a inversão da ordem posta, isto é, de o credor ter que provocar o Judiciário para a satisfação do seu crédito, verdadeiramente imporia uma sanção política, pois que não seria outro o intuito senão, mediante ato de império, induzir o devedor a satisfazer o débito apontado. Por arrastamento, foram também declarados inconstitucionais os arts. $6^{\circ}$ a 10 e 21 a 32 da Portaria PGFN 33/2018 (PROCURADORIA, 2018a), regulamentadores dos dispositivos legais objeto de controle de constitucionalidade (BRASIL, Supremo Tribunal Federal, 2020a).

Igualmente em relação à pretensa inconstitucionalidade material, Glauber Mesquita e Rafhael Frattari descrevem, como causas fundantes a estas, a reserva de jurisdição, a ampla defesa e a conjugação do direito de propriedade com a proporcionalidade (MESQUITA; FRATTARI, 2018).

$\mathrm{Na}$ mesma senda, Fernanda Ribeiro e Leonardo Machado sustentam a inconstitucionalidade material, reforçando o fundamento da proporcionalidade, que entendem violado pela indisponibilidade administrativa (RIBEIRO; MACHADO, 2018).

Inaugurando divergência, o ministro Dias Toffoli votou pelo reconhecimento de constitucionalidade da norma impugnada, ao fundamento de se tratar de mero "ato de registro", o que não ofenderia, desta feita, a cláusula de reserva de jurisdição e os princípios do contraditório e da ampla defesa, no que foi acompanhado pelos Ministros Alexandre de Moraes (SUPREMO, 2020b), Rosa Weber e Carmen Lúcia (SUPREMO, 2020c).

Lado outro, o Ministro Luis Roberto Barroso divergiu das compreensões precedentes, expondo entendimento quanto à constitucionalidade do lançamento de averbação, mas não relativamente à automática indisponibilidade, a qual exigiria reserva de jurisdição. Igualmente, votaram os ministros Gilmar Mendes, Ricardo Lewandowski e Luiz Fux (SUPREMO, 2020c).

Dessarte, por maioria, o STF, nos termos do voto médio do ministro Luis Roberto Barroso, julgou parcialmente procedentes os pedidos lançados nas já citadas ADI’s, de modo a considerar inconstitucional a expressão “... tornando-os indisponíveis”, descrita na parte final do inciso III do $\S 3^{\circ}$ do art. 20-B da Lei 10.522/02 (BRASIL, 2002), com a redação que lhe foi emprestada pela Lei 13.606/18 (BRASIL, 2018).

\section{ANÁLISE CRÍTICA DO JULGADO}


Malgrado tenha o STF reconhecido a inconstitucionalidade do lançamento administrativo de indisponibilidade de bens, o próprio tribunal - não em razão disto, mas também pelo fato de o julgamento ter sido por maioria - não fica vinculado ${ }^{6}$ ao julgado, da mesma forma que a função legislativa, a qual pode, novamente, se debruçar sobre o assunto.

Neste artigo, defende-se posicionamento divergente em relação ao vencedor, por maioria, no Supremo Tribunal Federal.

Em relação ao modelo descrito na LEF, Arnaldo Godoy afirma que se esgota pela própria seiva e, portanto, exige alternativa (GODOY, 2009).

Esta, no entanto, não pressupõe descaso em relação à ação de execução fiscal, mas a sua oxigenação procedimental, o que, pelo menos na esfera federal, foi alcançada pela Lei 10.522/02 (BRASIL, 2002), com redação advinda da Lei 13.606/18 (BRASIL, 2018). Ainda que inicialmente, em prol exclusivamente da União, entende-se pela inexistência de óbice jurídico para a incorporação da sistemática ${ }^{7}$ pela LEF, de aplicação indistinta a todas as esferas de governo: União, Estados, Distrito Federal e Municípios.

Não há razão jurídica para que meios alternativos à ação de execução fiscal revelem, via de regra, índices percentuais substancialmente superiores a esta quanto à arrecadação tributária.

O procedimento judicial pensado de forma desburocratizada, dotando a Fazenda Pública de prerrogativas procedimentais para a rápida e eficiente consecução do seu objetivo, não pode ceder tamanho espaço a formas utilizadas incidentalmente ao fim arrecadatório, a exemplo do protesto.

Não se defende uma exclusividade da ação judicial, mas sim uma revisitação desta, a fim de que lhe seja conferida eficiência, sem desgarrar-se do devido processo legal, ainda que para tanto se tenha que mesclar o procedimento, em esferas administrativa e judicial.

Pois bem.

\footnotetext{
${ }^{6}$ Não se desconhece a Teoria da Relativização da Não Vinculação, a qual, no entanto, opera efeitos em relação ao necessário resultado de improcedência de uma Ação Declaratória de Constitucionalidade (ADC) que verse sobre o tema julgado nas ADI’s referidas, face ao caráter dúplice/ambivalente das ações de controle concentrado de constitucionalidade.

${ }^{7}$ Atinente à averbação pré-executória, pois que o ajuizamento seletivo é corolário do princípio da eficiência, constitucionalmente garantido, e por tal razão, com alcance também ao Distrito Federal, Estados e Municípios, independentemente da edição de norma infraconstitucional neste sentido.
} 
Sob a perspectiva formal, tida por inconstitucional por 03 ministros do STF, inobstante se revele tese vencida, merece breve comentário à margem dos descritos no julgado quanto à mera regulamentação de procedimento.

Entende-se descabida a inclusão interpretativa, na locução "crédito tributário" de todos os instrumentos legais destinados à sua cobrança.

Isto porque quando a $\mathrm{CR} / 88$ intentou dispor sobre normas atinentes à cobrança, o fez de maneira clara e textual, o que se extrai dos arts. 146, IV e 149-A, parágrafo único. Percebase que no âmbito do próprio art. 146 da CR/88, utilizado pelo ministro Marco Aurélio, relator, para a extensiva interpretação do termo "crédito tributário" há menção ao termo "cobrança", de modo destacado em relação àquele.

Leonardo de Andrade Alvim, ao classificar como garantia “... qualquer instrumento processual ou material, previsto em lei, que vise ao recebimento do crédito tributário pelo Fisco..." entende que, mesmo se cogitando a subsunção da hipótese descrita ao art. 146, III, "b" da CR/88, a inserção da averbação pré-executória, via lei ordinária, não remontaria qualquer mácula constitucional (ALVIM, 2018, p. 170).

Isto porque, com arrimo nos arts. 183 e 184 do CTN, descreve que o referido código, que detém status de lei complementar, versa normas gerais sobre garantias do crédito tributário, deixando aberta, no entanto, a possibilidade de garantias outras não expressamente previstas no referido comando legal, a depender da especificidade de um tributo ou de um bem (ALVIM, 2018). A título exemplificativo de garantia afeta ao crédito tributário, presente em lei ordinária, portanto, adicionalmente às prescritas em leis complementares, cita o art. $1^{\circ}$, parágrafo único Lei 9.492/97, que propicia à Fazenda Pública o protesto de título executivo extrajudicial (ALVIM, 2018).

Sob o enfoque material.

A Constituição da República Federativa do Brasil de 1988 prescreve no art. 5, LIV, que "ninguém será privado da liberdade ou de seus bens sem o devido processo legal", no qual, por certo, está inserida a disposição da Lei 10.522/02 (BRASIL, 2002) com redação advinda da Lei 13.606/18 (BRASIL, 2018).

A reserva de jurisdição, assim, entendida como a prática de atos somente por juízes, não é vislumbrada na hipótese, o que, v.g., ocorre em algumas situações descritas no direito brasileiro, a exemplo da Justiça Desportiva ou no juízo arbitral (ALVIM, 2018). 
João Aurino Melo Filho destaca que "Se a Administração possui a prerrogativa da autotutela, executiva (autoexecutoriedade), pode satisfazer diretamente sua pretensão jurídica, sem necessidade de autorização ou da intervenção do Judiciário.” (MELO FILHO, 2017, p. $42)$.

A execução fiscal administrativa, ou híbrida, conglobando esta esfera com a Judicial, seria, portanto, arrimada não só no precitado art. 5\%, LIV, da CR/88, mas também na qualidade de autoexecutoriedade dos atos administrativos, oriunda do poder de autotutela, já sedimentado de forma tranquila no âmbito judicial, a exemplo do enunciado 473 da súmula do STF (BRASIL, Supremo Tribunal Federal, 1969).

Ora, tendo o Supremo Tribunal Federal editado o respectivo enunciado, resta evidente que a autotutela não afronta qualquer aspecto do devido processo legal, quiçá quando arrimado em comando legislativo, a exemplo da Lei 13.606/18 (BRASIL, 2018), exarado pela função constitucionalmente competente para tanto.

Tanto assim o é que João Aurino Melo Filho elenca dispositivos normativos, e não poucos, que, a despeito de propiciarem atos administrativos executórios no ordenamento jurídico brasileiro, não foram atingidos por suscitação, quiçá declaração de inconstitucionalidade:

\footnotetext{
“... artigo 72, IV, V, VII e VIII, da Lei $\mathrm{n}^{\circ}$ 9.605, de 12 de fevereiro de 1998; [...] artigo 58 do Código das Águas (Decreto ${ }^{\circ} 24.643$, de 10 de julho de 1934); [...] artigo $7^{\circ}$ do Decreto-lei $n^{\circ} 3.365$, de 21 de junho de 1.941; [...] artigo 45 da Lei ${ }^{\circ}$ 9.784, de 29 de janeiro de 1999; na Lei $n^{\circ}$ 6.024, de 13 de março de 1974 [...];[...] artigo 90 do Decreto-lei $\mathrm{n}^{\circ} 73$, de 21 de novembro de 1966; na intervenção administrativa prevista na Lei Complementar $\mathrm{n}^{\circ}$ 109, de 29 d emaio de 2001 [...]; e ainda, a pena administrativa de perdimento de bens, prevista no artigo 105 do Decreto-lei $\mathrm{n}^{\circ} 37$, de 18 de novembro de 1966, e no artigo 23, $\S 1^{\circ}$, do Decreto-lei 1.445 de 7 de abril de 1976." (MELO FILHO, 2017, p. 43).
}

Dentre estes há hipótese de perdimento de bens, ou de desapropriação, com a inerente modificação de propriedade, o que não ocorre no caso de mero lançamento de indisponibilidade. Se é verdade de quem pode o mais (perdimento ou desapropriação), pode o menos (indisponibilidade), inexiste, também sob esta perspectiva, incongruência com o sistema constitucional brasileiro.

A fundamentação é servível, também, ao afastamento da suscitação da pretensa mácula ao direito de propriedade, o que, pelo destaque dos preceitos legais dispostos, e até mesmo constitucionais - art. $5^{\circ}$, XXIV da CR/88 - não ostenta qualidade de direito absoluto. 
Quanto ao descrito no art. 185-A, adere-se ao raciocínio de Leonardo Alvim, ao consignar que:

“... o fato de o CTN trazer procedimento e os requisitos necessários para que o juiz determine a indisponibilidade de bens não conduz ao raciocínio contrario sensu de que outras autoridades diferentes da judiciária não poderiam determinar medida de semelhante conteúdo.” (ALVIM, 2018, p. 175).

O referido autor contrapõe os institutos do art. 185-A do CTN à averbação préexecutória:

\footnotetext{
"A leitura analítica do art. 185-A, do CTN, expõe o seguinte roteiro: 1) o devedor é citado; 2) não paga a dívida; 3) não nomeia bens à penhora; 4) não são encontrados bens pelo oficial de justiça; 5) indisponibilidade de bens.

Por sua vez, uma análise das fases previstas na chamada averbação pré-executória da PGFN pode ser descrita da seguinte forma: 1) o devedor é notificado; 2) não paga a dívida; 3) não parcela a dívida; 4) não oferece bens à administração; 5) opta por não discutir a dívida no âmbito administrativo (PRDI); 6) indisponibilidade de bens; 7) há contraditório e ampla defesa sobre a indisponibilidade ocorrida." (ALVIM, 2018, p. 180).
}

Do combate dos procedimentos, as fases destacadas no original, algumas das quais protetoras do contribuinte, não encontram eco na indisponibilidade judicial.

Na mesma senda, a utilização da averbação pré-executória denota a consecução de uma sequência de atos omissivos do sujeito passivo quanto ao intento de pagamento do tributo devido. Eduardo Gomes descreve que não se trata de mero ato discricionário, lançado pela existência de débitos pendentes de pagamento (GOMES, 2019).

Nesse sentido, lembrando a possibilidade de expropriação de bens de forma administrativa em âmbito de desapropriação, restando ao Judiciário apenas a discussão do valor devido, Flávio Bernardes e Henrique de Azevedo, inobstante avessos à possibilidade de execução fiscal administrativa, asseveram que o singelo argumento de ofensa do princípio do devido processo legal, face à não participação do Judiciário, não é suficiente a afastar a aplicação do instituto. Entendem que execução fiscal administrativa somente pode ser levada a efeito se não obstaculizar que o contribuinte participe do procedimento, salvaguardando-lhe os princípios constitucionalmente descritos e inerentes ao Estado Democrático de Direito: isonomia, garantia da propriedade privada, contraditório e ampla defesa (BERNARDES; DE AZEVEDO, 2017). 
E na regulamentação da Lei 10.522/02 (BRASIL, 2002), por meio da Portaria PGFN 33/2018 (PROCURADORIA, 2018a), a efetiva participação do sujeito passivo é, de fato, assegurada.

Não se olvide que em relação à execução fiscal, forte nos dados divulgados pelo IPEA (INSTITUTO, 2012), quase metade das ações não atingem êxito na citação ou esta é realizada de forma ficta, mediante publicação de edital, o que não pressupõe a efetiva cientificação do executado.

Assim sendo, ao contrário do suscitado, entende-se que o procedimento híbrido, rechaçado pelo STF, por maioria, pressupõe a fortificação do devido do processo legal, o qual não é exclusivo da seara jurisdicional, além de atingir o desiderato de forma mais eficiente do que a sistemática puramente judicial descrita na LEF.

Apesar do exposto, é inescapável a verificação de que a ação de execução fiscal, até então no âmbito federal, foi legislativa, e por tal razão também executivamente oxigenada pela norma tida por inconstitucional em parte, dando-se-lhe respiro e esperança de que ressurja como importante instrumento servível, sob o prisma da eficiência, aos credores tributários para recuperação do que não lhes foram pagos tempestivamente.

Ocorre que o alento à ação sob enfoque, experimentado por meio do seu incremento procedimental, conglobando fase administrativa à judicial, deparou-se com arguição de inconstitucionalidade, e, prevalente o entendimento majoritário exposto pelo STF, retorna o executivo fiscal ao já esgotado procedimento previsto na LEF, ou ao amputado desencadeamento de atos descrito na Lei 10.522/02 (BRASIL, 2002), destinando a arrecadação tributária à sorte da vontade dos executados em pagarem o tributo, sem efetivo e atual instrumento coercitivo a tanto.

Não se estranha, desta feita, que cada vez mais se utilize menos da ação de execução fiscal, e que os credores tributários passem a tatear a possibilidade de utilização de meios diversos ao prescrito na Lei 6.830/80 (BRASIL, 1980). E que neste caminho também percorrerá a União, relativamente à Lei 10.522/02 (BRASIL, 2002), após a tolhida de faculdades procedimentais pelo STF.

Por consequência direta, o impacto desta "inexecução fiscal" é revelado por meio de agravamento no cenário de crise - inclusive fiscal -, tornando paradoxo o fato de cada vez mais haver necessidade de consecução de políticas públicas - e para um número crescente de 
cidadãos -, no entanto, em viés diametralmente oposto, com a minoração arrecadatória do tributo não pago tempestivamente, principal fator de financiamento estatal.

No ano de 2017, apurado por meio do Relatório PGFN em números 2018, foram arrecadados, via ação de execução fiscal, R\$ 5,280 bilhões (PROCURADORIA, 2018b), ao passo que no exercício seguinte, em 2018, consoante dados do Relatório PGFN em números 2019, o montante cresceu 11,13\%, atingindo-se R\$ 5,868 bilhões. (PROCURADORIA, 2019).

A verificação apressada dos números pode indicar a falsa sensação de que nada de errado existe com o procedimento da ação de execução fiscal, a qual estaria demonstrando exuberante percentual de crescimento satisfativo.

No entanto, verifica-se por meio do Relatório PGFN em números 2020 (dados do ano de 2019), um aumento percentual vertiginoso, de 21,14\% em relação ao ano anterior, atingindo-se a cifra de $\mathrm{R} \$ 7,109$ bilhões, o que denota a conjunção de uma série de fatores para tanto, e não um milagroso recrudescimento qualitativo e quantitativo do executivo fiscal. (PROCURADORIA, 2020).

Certamente um dos fatores versa a respeito das contribuições legislativas advindas da Lei 13.606/18 (BRASIL, 2018), sendo certo que 2019 foi o primeiro - e último, ao menos quanto à integralidade dos seus dispositivos - ano inteiro (de janeiro a dezembro) de vigência dos institutos aperfeiçoadores da cobrança da dívida ativa, regulamentados pela Portaria PGFN 33/2018 (PROCURADORIA, 2018a).

O resultado espelha um crescimento percentual arrecadatório, via ação de execução fiscal, de quase o dobro do período antecedente (ano base 2018), sendo óbvia a ingerência da atuação estratégica derivada da alteração legislativa e regulamentação respectiva, acima lançadas.

Ainda, o procedimento de averbação pré-executória, descrito na Lei 10.522/02 (BRASIL, 2002), não deve ser qualificado como sanção política, pois que além de não inovar no sistema jurídico pátrio, em verdade, apenas prevê, via processo legislativo, atuação voltada à eficiência - incluída a economicidade - em correlação com o procedimento já estabelecido com o fim específico de arrecadação tributária, qual seja, o prescrito na LEF. Não há inovação, mas somente aperfeiçoamento do procedimento da ação de execução fiscal, o que o desnatura como pretenso meio indireto à cobrança tributária, a exemplo do que ocorre com a apreensão de mercadorias, hipótese por excelência de sanção política. 


\section{CONCLUSÃO}

É cediço que os tributos têm substancial correlação com a implementação de políticas públicas, pois que abastecem os cofres dos entes federativos, possibilitando-os a consecução dos deveres - para a Administração Pública - e dos direitos - dos cidadãos constitucionalmente postos na analítica Constituição da República Federativa do Brasil de 1988.

Desta forma, o inadimplemento tributário gera nefastas consequências, o que reclamou a formatação de uma ação judicial executiva suficiente, desburocratizada e célere o bastante para que o gestor público reouvesse o valor que não fora objeto de tempestivo pagamento e pudesse, se possível, ainda durante o seu mandato, geri-lo da melhor maneira.

Para tanto, a ação de execução fiscal foi pensada como meio propício e eficiente à arrecadação do tributo não pago a tempo e modo, estabelecendo-se, para tanto, procedimento diferenciado em relação à execução "geral", regulamentada pelo Código de Processo Civil.

Face à imprestabilidade da ação sob enfoque para a recuperação de crédito, entendese salutar a tentativa legislativa de revisitação procedimental, ainda que de modo inicial tenha sido destinada, exclusivamente, à União.

O entendimento sedimentado no julgamento da ADI 5881, pelo STF, por maioria, qual seja, o reconhecimento de inconstitucionalidade de averbação pré-executória, revela inconsistências jurídicas superadas em tópico específico deste artigo, o que impõe à toda a coletividade brasileira a manutenção de agonizante procedimento de execução fiscal, destinando a arrecadação tributária à sorte da vontade dos executados em pagarem o tributo, sem efetivo e atual instrumento coercitivo a tanto.

Não se estranha, desta feita, que cada vez mais se utilize menos da ação de execução fiscal, e que os credores tributários passem a tatear a possibilidade de utilização de meios diversos ao prescrito na LEF.

Por consequência direta, o impacto de manutenção da "inexecução fiscal" é revelado por meio de agravamento no cenário de crise - inclusive fiscal -, tornando paradoxo o fato de cada vez mais haver necessidade de consecução de políticas públicas - e para um número crescente de cidadãos -, no entanto, em viés diametralmente oposto, com a minoração arrecadatória do tributo não pago tempestivamente, principal fator de financiamento estatal. 


\section{REFERÊNCIAS}

ALVIM, Leonardo de Andrade Rezende. Averbação Pré-Executória pela PGFN. In: HENRIQUES, Guilherme de Almeida; GODOI, Marciano Seabra de; BONITO, Rafhael Frattari; LOBATO, Valter de Souza. (Coords.). Os impactos do novo CPC sobre o Processo Judicial Tributário, v.3. Belo Horizonte: D’Plácido, 2018.

BERNARDES, Flávio Couto; DE AZEVEDO, Henrique Machado Rodrigues. A execução fiscal administrativa: um olhar sobre a perspectiva da ampla defesa como integrante do feixe de garantias constitucionais que compõem o devido processo legal. Revista de Direito Tributário e Financeiro. Maranhão, v.3, n.2, p. 45-67, jul./dez. 2017.

BRASIL. Constituição da República Federativa do Brasil de 1988. Disponível em: http://www.planalto.gov.br/ccivil_03/constituicao/constituicao.htm. Acesso em: 25 jun. 2021.

BRASIL. Lei 5.172, de 25 de outubro de 1966. Dispõe sobre o Sistema Tributário Nacional e institui normas gerais de direito tributário aplicáveis à União, Estados e Municípios. Disponível em: http://www.planalto.gov.br/ccivil_03/leis/15172.htm. Acesso em: 13 jul. 2021.

BRASIL. Lei 5.869, de 11 de janeiro de 1973. Institui o Código de Processo Civil. Disponível em: http://www.planalto.gov.br/ccivil_03/LEIS/L5869impressao.htm. Acesso em: 13 maio. 2021.

BRASIL. Lei 6.830, de 22 de setembro de 1980. Dispõe sobre a cobrança judicial da Dívida Ativa da Fazenda Pública, e dá outras providências. Disponível em: http://www.planalto.gov.br/ccivil_03/leis/16830.htm. Acesso em: 13 maio. 2021.

BRASIL. Lei 10.522, de 19 de julho de 2002. Dispõe sobre o Cadastro Informativo dos créditos não quitados de órgãos e entidades federais e dá outras providências. Disponível em: http://www.planalto.gov.br/ccivil_03/leis/2002/110522.htm. Acesso em: 18 jun. 2021.

BRASIL. Lei Complementar 118, de 09 de fevereiro de 2005. Altera e acrescenta dispositivos à Lei $\mathrm{n}^{\mathrm{0}}$ 5.172, de 25 de outubro de 1966 - Código Tributário Nacional, e dispõe sobre a interpretação do inciso I do art. 168 da mesma Lei. Disponível em:

http://www.planalto.gov.br/ccivil_03/leis/lcp/lcp118.htm. Acesso em: 19 jun. 2021.

BRASIL. Lei 13.606, de 09 de janeiro de 2018. Institui o Programa de Regularização Tributária Rural (PRR) na Secretaria da Receita Federal do Brasil e na Procuradoria-Geral da Fazenda Nacional; altera as Leis $\mathrm{n}^{\mathrm{o}} \mathrm{s} 8.212$, de 24 de julho de 1991, 8.870, de 15 de abril de 1994, 9.528, de 10 de dezembro de 1997, 13.340, de 28 de setembro de 2016, 10.522, de 19 de julho de 2002, 9.456, de 25 de abril de 1997, 13.001, de 20 de junho de 2014, 8.427, de 27 de maio de 1992, e 11.076, de 30 de dezembro de 2004, e o Decreto-Lei no 2.848, de 7 de dezembro de 1940 (Código Penal); e dá outras providências. Disponível em: http://www.planalto.gov.br/ccivil_03/_Ato2015-2018/2018/Lei/113606.htm. Acesso em: 18 jun. 2021. 
BRASIL. Supremo Tribunal Federal. Ação Direta de Inconstitucionalidade 5881, Relator Ministro Marco Aurélio. Tribunal Pleno. Voto do Relator proferido em 05/06/2020. Julgamento não finalizado. Disponível em: https://www.conjur.com.br/dl/marco-aurelio-stfaverbacao-tributaria.pdf. Acesso em: 17 jun. 2021.

BRASIL. Supremo Tribunal Federal. Enunciado de súmula 473. A administração pode anular seus próprios atos, quando eivados de vícios que os tornam ilegais, porque deles não se originam direitos; ou revogá-los, por motivo de conveniência ou oportunidade, respeitados os direitos adquiridos, e ressalvada, em todos os casos, a apreciação judicial. Publicado em 10/12/1969. Disponível em:

http://www.stf.jus.br/portal/jurisprudencia/menuSumarioSumulas.asp?sumula=1602. Acesso em: 14 jul. 2021.

CAIS, Cleide Previtalli. O processo tributário. 8. ed. São Paulo. Revista dos Tribunais, 2013.

CONSELHO Nacional de Justiça. Relatório Justiça em Números 2019. Brasília: CNJ, 2019.

CONSELHO Nacional de Justiça. Relatório Justiça em Números 2020. Brasília: CNJ, 2020.

FONSECA, Rafael Campos Soares da; FONSECA, Gabriel Campos Soares da. A legitimidade política da execução fisscal na justiça federal brasileira. Revista Acadêmica da Faculdade de Direito do Recife. Recife, v. 89, n. 1, p. 30-49, jan./jun.2017.

GODOY, Arnaldo Sampaio de Moraes. A Execução Administrativa no Direito Tributário Comparado. Belo Horizonte: Fórum, 2009.

GOMES, Anderson Ricardo. Necessária mudança de paradigma na cobrança de créditos tributários no Brasil. Revista Justiça Fiscal. Brasília, Ano 8. n. 29, p.17-29, jan./abr. 2017. Disponível em: http://www.sinprofaz.org.br/2014/publicacao.php?id=revista-justica-fiscal29\&arquivo=/images/stories/pdfs/revistas/revista-justica-fiscal-

29.pdf\&titpub=Revista\%20Justi\%C3\%A7a\%20Fiscal\%20-

$\% 2029 \%$ C2\%AA\%20Edi\%C3\%A7\%C3\%A3o\&ml=5\&mlt=system\&tmpl=component. Acesso em: 23 maio 2021.

INSTITUTO DE PESQUISAS ECONÔMICAS APLICADAS (IPEA). Custo e tempo do processo de execução fiscal promovido pela Procuradoria Geral da Fazenda Nacional. Comunicado 127, de 04 jan. 2012. Disponível em:

https://www.ipea.gov.br/portal/images/stories/PDFs/comunicado/120103_comunicadoipea12 7.pdf. Acesso em: 13 jul. 2021.

MACHADO SEGUNDO. Hugo de Brito. Processo Tributário. 7. ed. São Paulo: Atlas, 2014.

MELO FILHO, João Aurino de. Sistemas de Cobrança Executiva da Obrigação Tributária no Direito Comparado: Execução Fiscal Administrativa como Modelo Moderno de Cobrança da Administração Tributária de Massas. Revista Justiça Fiscal. Brasília. Ano 8. n. 29, p.33-49, 
jan./abr. 2017. Disponível em: http://www.sinprofaz.org.br/2014/publicacao.php?id=revistajustica-fiscal-29\&arquivo=/images/stories/pdfs/revistas/revista-justica-fiscal-

29.pdf\&titpub=Revista\%20Justi\%C3\%A7a\%20Fiscal\%20-

$\% 2029 \% \mathrm{C} 2 \% \mathrm{AA} \% 20 \mathrm{Edi} \% \mathrm{C} 3 \% \mathrm{~A} 7 \% \mathrm{C} 3 \% \mathrm{~A} 3 \mathrm{o} \& \mathrm{ml}=5 \& \mathrm{mlt}=$ system\&tmpl=component .

Acesso em: 21 maio 2021.

MESQUISTA, Glauber; FRATTARI, Rafhael. Averbação pré-executiva: breve análise. In: HENRIQUES, Guilherme de Almeida; GODOI, Marciano Seabra de; BONITO, Rafhael Frattari; LOBATO, Valter de Souza. (Coords.). Os impactos do novo CPC sobre o Processo Judicial Tributário, v.3. Belo Horizonte: D’Plácido, 2018.

MINISTÉRIO da Justiça. Estudo sobre Execuções Fiscais no Brasil. São Paulo, 2007. Disponível em: http://heltonkramer.com/wp-content/uploads/2015/11/Minist\%C3\%A9rio-daJusti\%C3\%A7a-Secretaria-de-Reforma-do-Judici\%C3\%A1rio-Estudo-sobreExecu\%C3\%A7\%C3\%B5es-Fiscais-no-Brasil1.pdf. Acesso em: 13 jul. 2021.

PROCURADORIA Geral da Fazenda Nacional. Portaria 33, de 08 de fevereiro de 2018. Regulamenta os arts. 20-B e 20-C da Lei no 10.522, de 19 de julho de 2002 e disciplina os procedimentos para o encaminhamento de débitos para fins de inscrição em dívida ativa da União, bem como estabelece os critérios para apresentação de pedidos de revisão de dívida inscrita, para oferta antecipada de bens e direitos à penhora e para o ajuizamento seletivo de execuções fiscais.

PROCURADORIA Geral da Fazenda Nacional. PGFN em números 2018. PGFN, 2018.

PROCURADORIA Geral da Fazenda Nacional. PGFN em números 2019. PGFN, 2019.

PROCURADORIA Geral da Fazenda Nacional. PGFN em números 2020. PGFN, 2020.

PROCURADORIA Geral da Fazenda Nacional. Protesto de CDAs possui taxa de recuperação de 19\%. PGFN, 21 jun. 2016. Disponível em:

http://www.pgfn.fazenda.gov.br/noticias/2016/protesto-de-cdas-possui-taxa-de-recuperacaode-19\#: :text=noticias-

,Protesto\%20de\%20CDAs\%20possui\%20taxa\%20de\%20recupera\%C3\%A7\%C3\%A3o\%20d e\%2019\%25,recuperam\%20apenas\%201\%25\%20das\%20d\%C3\%ADvidas. Acesso em: 13 jun. 2021.

QUEIROZ E SILVA, Jules Michelet Pereira. Execução fiscal: eficiência e experiência comparada. Câmara dos Deputados, julho 2016. Disponível em:

https://www2.camara.leg.br/atividade-legislativa/estudos-e-notas-tecnicas/publicacoes-daconsultoria-legislativa/areas-da-conle/tema20/2016_12023_execucao-fiscal-eficiencia-eexperiencia-comparada_jules-michelet. Acesso em: 30 maio 2021.

RIBEIRO, Fernanda Prata Moreira; MACHADO, Leonardo Resende Alvim. As alterações da lei $n^{\circ}$ 13.606/2018 e os seus impactos na ordem processual tributária. In: HENRIQUES,

Guilherme de Almeida; GODOI, Marciano Seabra de; BONITO, Rafhael Frattari; LOBATO, Valter de Souza. (Coords.). Os impactos do novo CPC sobre o Processo Judicial

Tributário, v.3. Belo Horizonte: D’Plácido, 2018. 
RIBEIRO, Maria de Fátima; NUNES, Geilson; ALMEIDA, Patrícia Silva de. O desenvolvimento dos direitos fundamentais através da tributação: políticas públicas como fomento do bem-estar social. Revista Meritum, v. 13, n. 1, p. 128-146, jan./jun., 2018. Disponível em: http://www.fumec.br/revistas/meritum/article/view/5827/pdf_1. Acesso em: 19 jun. 2021.

SUPREMO TRIBUNAL FEDERAL. Pleno - Indisponibilidade de bens de devedor contribuinte - COM AUDIODESCRIÇÃO. 2020. Disponível em:

https://www.youtube.com/watch?v=ukIBVi-vkgo. Acesso em: 07 jun. 2021.

SUPREMO TRIBUNAL FEDERAL. Pleno - Indisponibilidade de bens de devedor contribuinte (1/2) - COM AUDIODESCRIÇÃO. 2020. Disponível em:

https://www.youtube.com/watch?v=yyyiOt_ST3M. Acesso em: 07 jun. 2021.

SUPREMO TRIBUNAL FEDERAL. Pleno - Indisponibilidade de bens de devedor contribuinte (2/2) - COM AUDIODESCRIÇÃO. 2020. Disponível em:

https://www.youtube.com/watch?v=QHYFIKR_qbw. Acesso em: 07 jun. 2021. 